\section{BMJ Paediatrics Open}

\title{
Paediatric dermatological conditions in an emergency department: a single- centre study in Thailand
}

\author{
Leelawadee Techasatian (D) , ${ }^{1}$ Rattapon Uppala, ${ }^{1}$ Pariwat Phungoen ${ }^{2}$
}

To cite: Techasatian $L$, Uppala R, Phungoen P. Paediatric dermatological conditions in an emergency department: a singlecentre study in Thailand. BMJ Paediatrics Open 2021;5:e001215. doi:10.1136/ bmjpo-2021-001215

Received 2 July 2021 Accepted 24 August 2021

\section{Check for updates}

\section{(C) Author(s) (or their} employer(s)) 2021. Re-use permitted under CC BY-NC. No commercial re-use. See rights and permissions. Published by BMJ.

${ }^{1}$ Pediatric, Khon Kaen University Faculty of Medicine, Khon Kaen, Thailand

${ }^{2}$ Emergency, Khon Kaen University Faculty of Medicine, Khon Kaen, Thailand

\section{Correspondence to} Dr Leelawadee Techasatian; leelawadee@kku.ac.th

\section{ABSTRACT}

Background Few studies have evaluated paediatric dermatological conditions and their associated factors that warrant admission at the emergency department.

Objectives The main objective of this study was to present the demographic information of paediatric dermatological conditions encountered in the emergency department and identify possible associated factors for hospital admission.

Methods This retrospective cross-sectional study included paediatric patients who visited the emergency department between 1 January 2016 and 31 December 2019. Data collection was performed using an authorised electronic medical records programme at Srinagarind Hospital, Faculty of Medicine, Khon Kaen University, Thailand.

Results A total of 40683 paediatric patients visited the emergency department during the study period, with 1701 cases presenting dermatological conditions. Infections were the most frequent conditions encountered in the emergency department $(647,38.0 \%)$, followed by urticaria/anaphylaxis (478, 28.1\%), eczematous diseases (463, 27.2\%), cutaneous drug eruptions (64, 3.7\%) and miscellaneous (49, $2.9 \%$ ). Among 1701 paediatric cases with dermatological conditions, only 182 cases (10.7\%) were admitted to the hospital and required further management. Cases presenting cutaneous drug eruptions had the highest proportion of hospital admissions $(60.9 \%)$ and were significantly different from cases in other dermatologic categories $(p<0.001)$. The association of admission found an $\mathrm{OR}$ of 0.96 for every year of increase in age $(95 \% \mathrm{Cl} 0.93$ to $0.99, \mathrm{p}=0.003)$.

Conclusion The present study found that the majority of patients with cutaneous conditions visiting the emergency department were non-urgent; however, dermatological emergencies exist and should not be underestimated. Younger paediatric patients presenting with dermatological condition is a population with a high risk for hospital admission. Cutaneous drug eruptions showed the highest proportion of hospital admissions compared with other dermatological categories. Therefore, physicians in the emergency department should always look for specific cutaneous signs of drug eruptions, such as target-like lesions and mucosal involvement in StevenJohnsons syndrome/toxic epidermal necrolysis to prevent misdiagnosis of this dermatological condition.

\section{INTRODUCTION}

Skin conditions appear to be common in non-emergency outpatient settings and can

\section{What is known about the subject?}

- The majority of patients with cutaneous conditions visiting the emergency department were nonurgent; however, dermatological emergencies exist and should not be underestimated.

\section{What this study adds?}

Among paediatric cases with dermatological conditions, cutaneous drug eruptions showed the highest proportion of hospital admissions compared with other dermatological categories.

- Physicians in the emergency department should always look for specific cutaneous signs of drug eruptions, such as target-like lesions, and mucosal involvement in Steven-Johnsons syndrome/toxic epidermal necrolysis, to prevent underdiagnosis or misdiagnosis of this dermatological condition.

- Younger paediatric patients presenting with dermatological conditions is a population of concern with a high potential for hospital admission.

be safely monitored with minimal intervention. ${ }^{1}$ However, in an emergency context, there were also numerous patient complaints of cutaneous conditions. ${ }^{23}$ In an adult population, there are reports of approximately $5 \%-8 \%$ of dermatological diseases present among all emergency department visits. ${ }^{4-8} \mathrm{~A}$ recent publication also showed a significant number of cutaneous conditions in the paediatric population in emergency departments in the USA; however, only $2.1 \%$ of patients with dermatologic conditions required further observation or hospital admission. ${ }^{9}$ There are few published reports on paediatric dermatology in the emergency department; indeed, scarce data exist regarding the characteristics of these patients. There are specific skin conditions that are emergent and require immediate attention and proper assessment. Thus, the present study aimed to explore the prevalence, demographic characteristics and possible associated factors 
for hospital admissions related to dermatologic conditions in the paediatric population ( $\leq 18$ years of age) in an emergency department at a tertiary care hospital in Thailand. The results may provide physicians in an emergency context with information regarding frequency of emergent causes of dermatologic conditions.

\section{METHODS}

\section{Study design}

The authors conducted a cross-sectional epidemiological study from 1 January 2016 to 31 December 2019 by collecting data from the Health Object Program, an authorised electronic medical records programme, at the Srinagarind Hospital, Faculty of Medicine, Khon Kaen University, Thailand. All patients aged $\leq 18$ years presenting dermatological symptoms (including rashes, pruritic symptoms, papules, nodules and so on), that visited the Emergency Department of the Faculty of Medicine, Khon Kaen University were included in the study. The process of admission of paediatric patients in the present setting required paediatric consultation prior to admission. Hospital admission was based on the decision of on-call paediatricians. The diagnoses of the dermatological conditions were made by on-call paediatric dermatologists and expert paediatricians.

\section{Statistical analysis}

At the end of the study, the collected data were analysed using STATA software V.10 (StataCorp LP). The statistician modified the original data set (Excel format) by recoding, labelling variables and converting strings to numeric and categorical data before using the STATA analysis. Descriptive statistical methods, means, SDs, medians and frequencies were used to analyse the demographic data. Statistical significance was set at $p<0.05$. Pearson's $\chi^{2}$ was used to test the differences between categories. Univariate analysis was used to test the associations between possible factors and the hospital admission.

\section{Patient and public involvement}

Patients or the public were not involved in the design, conduct, reporting or dissemination plans of our research.

\section{RESULTS}

A total of 40683 paediatric patients ( $\leq 18$ years of age) visited the emergency department, with 1701 cases presenting dermatologic symptoms during the study period. There were 913 (53.7\%) male and 788 (46.3\%) female patients; thus, the ratio of male to female patients was 1.1. The ages of the patients ranged from 21 days to 18 years, with a median age of 6 years (IQR 2.3-12.1). The age range was classified into four groups: infants ( $<1$ year old), preschool-aged children (1-6 year old), school-aged children (7-12 year old) and adolescents (13-18 year old). Most patients were in the preschoolaged group $(38.2 \%)$, followed by adolescents $(25.2 \%)$, school-aged (24.2\%) and infants (12.4\%).
Dermatologic conditions were classified into five categories: eczematous diseases, urticaria/anaphylaxis, cutaneous drug eruptions, infections and miscellaneous. Infections were the most frequent dermatologic conditions that were encountered in the emergency department during the study period $(647,38.1 \%)$, followed by urticaria/anaphylaxis $(478,28.1 \%)$, eczematous diseases $(463,27.2 \%)$, cutaneous drug eruptions $(64,3.8 \%)$ and miscellaneous conditions (49, 2.9\%). Table 1 shows the demographic information of patients with dermatologic conditions in five different diagnostic categories in the study population.

Among the dermatologic conditions caused by infections, infectious exanthem was the most common (390 cases, $22.9 \%$ ), followed by specific/identified viral infections such as varicella infection, varicella zoster infection, herpes infection, hand foot mouth disease and infectious mononucleosis, among others (155 cases, 9.1\%). Bacterial infections were observed in 69 cases $(4.2 \%)$, and this subgroup showed the highest proportion of hospital admissions in the infections category (figure 1). Table 2 presents the distribution of cases in relation to the types of dermatological conditions.

Urticaria and/or anaphylaxis were classified into one group. There were 478 cases $(28.1 \%)$ in this category. Urticaria was observed in 395 cases (23.2\%) and anaphylaxis in 83 cases $(4.9 \%)$ (table 2 ).

Eczematous diseases were observed in 463 patients $(27.2 \%)$. The authors classified a presentation of this category into atopic dermatitis and unspecified dermatitis (non-atopic dermatitis) (table 2). None of the patients with eczematous diseases required hospital admission.

Drug eruptions in the study population included StevenJohnsons syndrome (SJS)/toxic epidermal necrolysis (TEN), maculopapular drug exanthem, drug rash with eosinophilia and systemic symptoms syndrome and other unspecified drug eruptions. This dermatologic category was observed in 64 cases $(3.7 \%)$ and had the highest proportion of admissions $(39 / 64,60.9 \%)$ compared with other dermatologic categories (Pearson's $\chi^{2}, \mathrm{p}<0.001$ ) (figure 2).

Among 1701 cases in the emergency department, most cases (1519 cases, $89.3 \%)$ were discharged after examination. Only 182 cases $(10.7 \%)$ were admitted to the hospital and required further management.

The present study performed an association test to determine the possible risk factors for admission using univariate analysis. The association of admission found an $\mathrm{OR}$ of 0.96 for every year of increase in age $(\mathrm{OR}=0.96$, $95 \%$ CI 0.93 to $0.99, \mathrm{p}=0.003$ ). Figure 3 shows the predicted probability of admission based on patient age.

\section{DISCUSSION}

The majority of cutaneous conditions in the paediatric population appear to be non-urgent and can be safely monitored; however, there are reports describing populations of paediatric patients presenting to the emergency 
Table 1 Demographic information of the patients with dermatologic conditions in five different diagnostic categories

\begin{tabular}{|c|c|c|c|c|c|c|}
\hline \multirow[b]{2}{*}{ Variable } & \multirow[b]{2}{*}{$\begin{array}{l}\text { Total } \\
(n=1701)\end{array}$} & \multicolumn{5}{|c|}{ Diagnosis category } \\
\hline & & $\begin{array}{l}\text { Eczematous } \\
\text { diseases } \\
(n=463)\end{array}$ & $\begin{array}{l}\text { Urticaria/ } \\
\text { anaphylaxis } \\
(n=478)\end{array}$ & $\begin{array}{l}\text { Drug eruptions } \\
(n=64)\end{array}$ & $\begin{array}{l}\text { Infections } \\
(n=647)\end{array}$ & $\begin{array}{l}\text { Miscellaneous } \\
(n=49)\end{array}$ \\
\hline \multicolumn{7}{|l|}{ Sex } \\
\hline Male & $913(53.7)$ & $240(51.8)$ & 285 (59.6) & 38 (59.4) & $334(51.6)$ & 16 (32.6) \\
\hline Female & 788 (46.3) & $223(48.2)$ & $193(40.4)$ & $26(40.6)$ & $313(48.4)$ & $33(67.4)$ \\
\hline Median (IQR) & $6(2.3-12.1)$ & 7.3 (3.2-13.3) & $8.2(3.4-14.6)$ & $4.9(1.7-11.3)$ & $4.4(1.8-8.4)$ & $7.2(2.1-14.7)$ \\
\hline \multicolumn{7}{|l|}{ Age group } \\
\hline Infant ( $\leq 1$ year) & $211(12.4)$ & $49(10.6)$ & $48(10.0)$ & $9(14.1)$ & $95(14.7)$ & $10(20.4)$ \\
\hline $\begin{array}{l}\text { Preschool age } \\
\text { (1-6 years) }\end{array}$ & $649(38.2)$ & $155(33.5)$ & $143(29.9)$ & $29(45.3)$ & $310(47.9)$ & $12(24.5)$ \\
\hline \multicolumn{7}{|l|}{ Admit } \\
\hline Yes & $182(10.7)$ & $0(0)$ & $82(17.2)$ & 39 (60.9) & $50(7.7)$ & $11(22.4)$ \\
\hline No & 1519 (89.3) & 463 (100.0) & 396 (82.9) & 25 (39.1) & 597 (92.3) & 38 (77.6) \\
\hline
\end{tabular}

department. ${ }^{10-13}$ In our study, the proportion of paediatric patients on this context is similar to that seen in previous studies (range 4\%-10\%). ${ }^{6}{ }^{14-16}$ Indeed, a study that explored urgent consultations for skin disorders among the paediatric population in a teaching hospital found that most cases were not true emergencies. ${ }^{17}$ Another study reported that $12 \%$ of cases were misdiagnoses and demonstrated the important role of the dermatologist in the diagnosis and management of paediatric patients with dermatological diseases. ${ }^{16}$

The paediatric population in Thailand is approximately 13 million children, which constitute approximately $19.9 \%$ of the total Thai population. ${ }^{18}$ The sex distribution of the general Thai paediatric population shows that the male to female ratio is $1.1,{ }^{18}$ which is similar to the

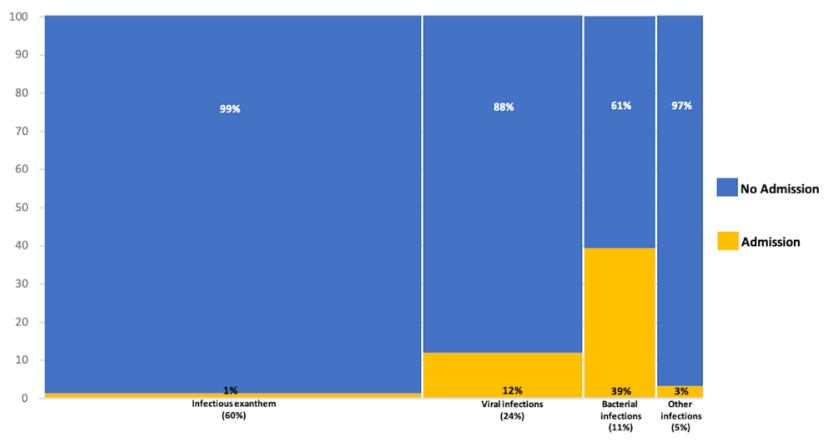

Figure 1 Mosaic plot of the proportion of admissions in infections category. Bacterial infections had the highest proportion of hospital admissions compared with infections from other causes, Pearson's $\chi^{2} p<0.001$. sex distribution of the population encountered in the present study. The most common cutaneous category in the present study was infection, which is in contrast to the study in France that found viral exanthem and atopic dermatitis to be the most common diagnoses. ${ }^{19}$ The study in France was conducted for a shorter period of time ( 5 months) and did not categorise cutaneous conditions in groups, as in the present study, which may have affected the results. However, a study in a paediatric population in the USA revealed that the diagnostic category of infections was the most common, ${ }^{20}$ as seen in the current study.

In the subgroup of bacterial infections, staphylococcal scaled skin syndrome is one of the dermatologic conditions that requires urgent treatment and five cases $(0.3 \%)$ in our population had this disease. It typically occurs in younger children and has a unique presentation of desquamation of the periorifices (around the eyes, mouth, genitalia and anus). A positive Nikolsky sign can be found for this disease, since the Staphylococcus aureus toxin targets desmoglein 1 complex in the zona granulosa of the epidermis, resulting in skin exfoliation. ${ }^{121} 22$ The present study shows that dermatological emergencies exist and should not be underestimated; therefore, physicians should be familiar with diseases in this category, especially in young children, to prevent misdiagnosis of emergency cutaneous conditions. ${ }^{23}$ The authors encourage physicians to pay close attention to cutaneous drug eruptions which are associated with an increased need for further intervention and hospital admission. Physicians in the emergency department should always look for specific cutaneous signs of drug allergy, such as 
Open access

Table 2 Distribution of cases in relation to the types of dermatological conditions

\begin{tabular}{|c|c|c|c|c|}
\hline Group & Subgroup & No. (\%) & & No. (\%) \\
\hline \multirow[t]{2}{*}{ Eczematous diseases } & & $463(27.2)$ & Atopic dermatitis & $152(8.9)$ \\
\hline & & & $\begin{array}{l}\text { Unspecify dermatitis (non- } \\
\text { atopic dermatitis) }\end{array}$ & $311(18.3)$ \\
\hline \multirow[t]{2}{*}{ Urticaria/anaphylaxis } & & $478(28.1)$ & Urticaria & $395(23.2)$ \\
\hline & & & Anaphylaxis & $83(4.9)$ \\
\hline \multirow[t]{4}{*}{ Drug eruptions } & & $64(3.7)$ & SJS/TEN & $3(0.2)$ \\
\hline & & & $\begin{array}{l}\text { Drug rash with eosinophilia } \\
\text { and systemic symptoms } \\
\text { (DRESS) syndrome }\end{array}$ & $3(0.2)$ \\
\hline & & & Maculopapular drug exanthem & $50(2.9)$ \\
\hline & & & Other drug eruptions & $8(0.5)$ \\
\hline \multirow[t]{20}{*}{ Infections } & Infectious exanthem & $390(22.9)$ & $\begin{array}{l}\text { Unspecified infectious } \\
\text { exanthem }\end{array}$ & $390(22.9)$ \\
\hline & Viral infections & $155(9.1)$ & Varicella infection (chicken pox) & $38(2.2)$ \\
\hline & & & Herpes infection & $40(2.4)$ \\
\hline & & & Herpes zoster infection & $19(1.1)$ \\
\hline & & & Molluscum contagiosum & $5(0.3)$ \\
\hline & & & Warts & $6(0.4)$ \\
\hline & & & Measles & $11(0.6)$ \\
\hline & & & $\begin{array}{l}\text { Infectious mononucleosis with } \\
\text { skin lesions }\end{array}$ & $21(1.2)$ \\
\hline & & & $\begin{array}{l}\text { Dengue infection with skin } \\
\text { lesions }\end{array}$ & $15(0.9)$ \\
\hline & Bacterial infections & $69(4.2)$ & $\begin{array}{l}\text { Staphylococcal scald skin } \\
\text { syndrome }\end{array}$ & $5(0.3)$ \\
\hline & & & Sepsis with skin lesions & $2(0.1)$ \\
\hline & & & Scarlet fever & $12(0.7)$ \\
\hline & & & Impetigo & $29(1.7)$ \\
\hline & & & Cellulitis & $9(0.5)$ \\
\hline & & & Abscess & $10(0.6)$ \\
\hline & & & Necrotising fasciitis & $2(0.1)$ \\
\hline & Other infections & $32(1.9)$ & Pityriasis versicolor & $14(0.8)$ \\
\hline & & & Dermatophyte infections & $10(0.6)$ \\
\hline & & & Candida infections & $6(0.4)$ \\
\hline & & & $\begin{array}{l}\text { Parasites (scabies, enterobius } \\
\text { vermicularis) }\end{array}$ & $2(0.1)$ \\
\hline \multirow[t]{5}{*}{ Miscellaneous } & & $49(2.9)$ & Acne & $9(0.5)$ \\
\hline & & & $\begin{array}{l}\text { Millia, miliria rubra, milliaria } \\
\text { crystallena }\end{array}$ & $4(0.2)$ \\
\hline & & & $\begin{array}{l}\text { Collagen vascular diseases } \\
\text { (SLE, dermatomyositis) }\end{array}$ & $11(0.6)$ \\
\hline & & & $\begin{array}{l}\text { Papulosquamous diseases } \\
\text { (psoriasis, pityriasis rubra } \\
\text { pilaris, pityriasis lichenoides) }\end{array}$ & $12(0.7)$ \\
\hline & & & Other inconclusive diagnosis & $13(0.8)$ \\
\hline Total & & & & $1701(100)$ \\
\hline
\end{tabular}

SJS, Steven-Johnsons syndrome; SLE, systemic lupus erythematosus; TEN, toxic epidermal necrolysis. 


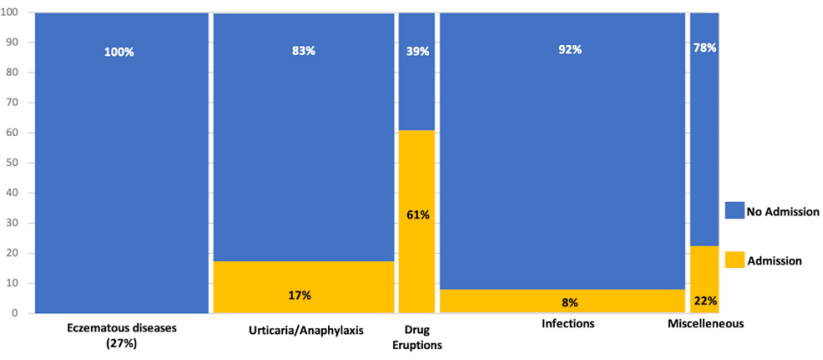

Figure 2 Mosaic plot of the proportion of hospital admissions among five different dermatological categories in the study population. Cutaneous drug eruptions had the highest proportion of hospital admissions compared with other groups, Pearson's $\chi^{2} \mathrm{p}<0.001$.

target-like lesions, and mucosal involvement in SJS/TEN to prevent underdiagnosis or misdiagnosis of diseases in this dermatologic category.

Although some patients with dermatologic conditions require further intevention and treatment, most patients in our study did not present true urgent dermatological conditions. There were some cases of acne, milia, miliaria and urticaria, as well as numerous cases of eczematous diseases, which are non-emergency conditions. The diagnoses of these dermatological conditions were made by on-call paediatric dermatologists and expert paediatricians, which indicates that dermatological education is essential among parents, caregivers and general physicians to determine whether the cutaneous conditions are truly emergent. Improving community care and outpatient dermatology clinics may help reduce the strain on the emergency department.

Drago et al reported some alarming features that can be observed in dermatological patients, ${ }^{3}$ which included dermal warning signs, systemic symptoms and laboratory findings, such as leukocytosis and thrombocytopenia. Some individual risk factors, such as drug exposure, were one of the alarming features observed by Drago and his colleagues. This result is in line with the present study, which found a significant difference in a high proportion of admissions in patients with cutaneous drug eruptions. Therefore, our results confirm that patients with

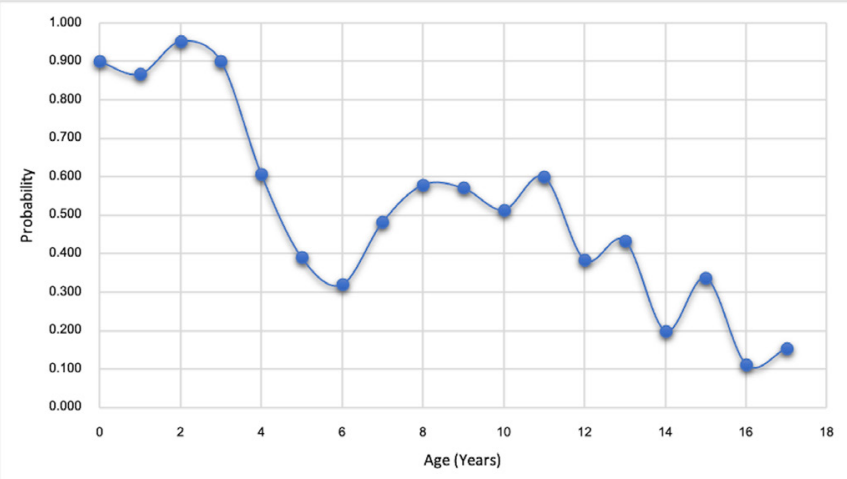

Figure 3 Predicted probability of admission based on patient age $(\mathrm{OR}=0.96,95 \% \mathrm{Cl} 0.93$ to $0.99, \mathrm{p}=0.003)$. a history of suspected drug allergy have an increased risk of presenting a serious dermatological condition that requires further assessment or hospital admission. Physicians in the emergency department should always look for specific cutaneous signs of drug allergy, such as target-like lesions, and mucosal involvement in SJS/TEN to prevent underdiagnosis or misdiagnosis of diseases in this dermatologic category.

A previous study in US paediatric hospitals revealed that the hospital-level and severity of illness were the factors associated with hospital admission for children among different emergency departments. ${ }^{24}$ In that study, variation among the common paediatric conditions that warrant hospital admissions was investigated; however, dermatological conditions were not included. The present study performed an association test to determine the possible risk factors of hospital admission, which revealed a $4 \%$ decrease in admission for every year of increase in age. Thus, younger paediatric patients presenting with dermatological conditions is a population with a high risk for hospital admission.

The main limitation of the present study was its retrospective design. There was a lack of information regarding some data, including data on the patients referred by the general physicians/primary physicians or other doctors versus those patients that simply presented to the emergency department, and unknown percentage of patients who were subsequently followed up in the hospital's dermatology clinic. Therefore, further assessments based on this type of data could not be made.

In conclusion, the present study found that the majority of paediatric patients with cutaneous conditions presenting to the emergency department were non-urgent cases; however, dermatological emergencies exist and should not be underestimated. Younger paediatric patients presenting with dermatological conditions constitute a population with an increased risk of hospital admission. Cutaneous drug eruptions showed the highest proportion of admissions compared with other dermatological categories. Therefore, physicians in the emergency department should always look for specific cutaneous signs of drug eruptions, such as target-like lesion and mucosal involvement in SJS/TEN, to prevent underdiagnosis or misdiagnosis of this dermatological disease.

Acknowledgements We would like to acknowledge Professor Gurdeep Singh for editing the MS via Publication Clinic KKU, Thailand, Ms Duangdao Sriruengrat for the statistical analysis, and Editage for English language editing in the revised manuscript. The study was approved by the Institutional Review Board of the Khon Kaen University, Human Research Ethics Committee (\#HE631595). The waiver for informed consent was approved, and all methods were performed in accordance with the relevant guidelines and regulations.

Contributors LT contributed to the conception and design of the study, data analysis, interpretation of findings, drafting of the article, revision of the article and final approval of the submitted version. RU and PP contributed to the study conception and data collection. All authors critically revised the article and approved the final version of the manuscript.

Funding The authors have not declared a specific grant for this research from any funding agency in the public, commercial or not-for-profit sectors. 
Competing interests None declared.

Patient and public involvement Patients and/or the public were not involved in the design, or conduct, or reporting, or dissemination plans of this research.

Patient consent for publication Not required.

Ethics approval The study was approved by the Institutional Review Board of the Faculty of Medicine, Khon Kaen University, Thailand (IRB no. \#HE631595). The authors covered patient data confidentiality and compliance with the Declaration of Helsinki. The present study used data from medical records, documents, records and image recordings that were previously collected for purposes other than research (eg, normal care or normal diagnosis) and did not affect the subjects' rights and well-being; thus, waiving the informed consent was approved by the IRB of the Faculty of Medicine, Khon Kaen University, Thailand.

Provenance and peer review Not commissioned; externally peer reviewed

Data availability statement Data sharing not applicable as no datasets generated and/or analysed for this study. Data are available upon reasonable request. The datasets generated during and/or analysed during the current study are available from the corresponding author on reasonable request.

Open access This is an open access article distributed in accordance with the Creative Commons Attribution Non Commercial (CC BY-NC 4.0) license, which permits others to distribute, remix, adapt, build upon this work non-commercially, and license their derivative works on different terms, provided the original work is properly cited, appropriate credit is given, any changes made indicated, and the use is non-commercial. See: http://creativecommons.org/licenses/by-nc/4.0/.

ORCID iD

Leelawadee Techasatian http://orcid.org/0000-0003-4668-6792

\section{REFERENCES}

1 Robinson SK, Jefferson IS, Agidi A, et al. Pediatric dermatology emergencies. Cutis 2020;105:132-6.

2 Uppala R, Phungoen P, Mairiang D, et al. Pediatric anaphylaxis: etiology and predictive factors in an emergency setting. Glob Pediatr Health 2021;8:2333794X211011301.

3 Drago F, Gasparini G, Signori A, et al. Dermatological consultations in an observation unit of an emergency department in Italy. $J$ Eur Acad Dermatol Venereol 2015;29:973-80.

4 Kilic D, Yigit O, Kilic T, et al. Epidemiologic characteristics of patients admitted to emergency department with dermatological complaints; a retrospective cross sectional study. Arch Acad Emerg Med 2019;7:e47.

5 McMahon P, Goddard D, Frieden IJ. Pediatric dermatology inpatient consultations: a retrospective study of 427 cases. J Am Acad Dermatol 2013;68:926-31.

6 Scarfone RJ, Luberti AA, Mistry RD. Children referred to an emergency department by an after-hours call center: complaintspecific analysis. Pediatr Emerg Care 2004;20:507-13.

7 Antic M, Conen D, Itin PH. Teaching effects of dermatological consultations on nondermatologists in the field of internal medicine. A study of 1290 inpatients. Dermatology 2004;208:32-7.
8 Shao E, Judge C, McMeniman E, et al. Presenting patterns of dermatology conditions to an Australian emergency department. World J Emerg Med 2020;11:74-8.

9 Collier EK, Yang JJ, Sangar S, et al. Evaluation of emergency department utilization for dermatologic conditions in the pediatric population within the United States from 2009-2015. Pediatr Dermatol 2021;38:449-54.

10 Ozkur E, Altunay I, Sekerlisoy G, et al. Evaluation of dermatology consultations in a tertiary care centre emergency service. Sisli Etfal Hastan Tip Bul 2020;54:197-200.

11 Techasatian L, Phungoen P, Chaiyarit J, et al. Etiological and predictive factors of pediatric urticaria in an emergency context. BMC Pediatr 2021;21:92.

12 Muzumdar S, Rothe MJ, Grant-Kels JM. The rash with maculopapules and fever in children. Clin Dermatol 2019;37:119-28.

13 Lai-Kwon J, Weiland TJ, Chong AH, et al. Which dermatological conditions present to an emergency department in Australia? Emerg Med Int 2014;2014:1-4.

14 Alpalhão M, Uva L, Soromenho G, et al. Dermatological emergencies: one-year data analysis of 8,620 patients from the largest Portuguese tertiary teaching hospital. Eur J Dermatol 2016;26:460-4.

15 Connolly DM, Silverstein DI. Dermatology consultations in a tertiary care Hospital: a retrospective study of 243 cases. Dermatol Online J 2015;21:13030.

16 Cruz-Manzano M, Brau-Javier CN, Valentín-Nogueras S, et al. Pediatric inpatient and emergency dermatology consultations: a 5year retrospective analysis. P R Health Sci J 2018;37:105-9.

17 Ruzza N, Itin PH, Beltraminelli H. Urgent consultations at the dermatology department of Basel University Hospital, Switzerland: characterisation of patients and setting - a 12-month study with 2,222 patients data and review of the literature. Dermatology 2014;228:177-82.

18 Thailand population (2021) live - Countrymeters [Internet]. Available: https://countrymeters.info/en/Thailand [Accessed 02 Aug 2021].

19 Auvin S, Imiela A, Catteau B, et al. Paediatric skin disorders encountered in an emergency Hospital facility: a prospective study. Acta Derm Venereol 2004;84:451-4.

20 Moon AT, Castelo-Soccio L, Yan AC. Emergency department utilization of pediatric dermatology (PD) consultations. J Am Acad Dermatol 2016;74:1173-7.

21 Leung AKC, Barankin B, Leong KF. Staphylococcal-scalded skin syndrome: evaluation, diagnosis, and management. World J Pediatr 2018;14:116-20.

22 Staiman A, Hsu DY, Silverberg Jl. Epidemiology of staphylococcal scalded skin syndrome in U.S. children. Br J Dermatol 2018;178:704-8.

23 Onsoi W, Chaiyarit J, Techasatian L. Common misdiagnoses and prevalence of dermatological disorders at a pediatric tertiary care center. J Int Med Res 2020;48:030006051987349.

24 Bourgeois FT, Monuteaux MC, Stack AM, et al. Variation in emergency department admission rates in US children's hospitals. Pediatrics 2014;134:539-45. 